\title{
A inter-relação da demanda e acessibilidade na Estratégia Saúde da Família
}

\author{
I ${ }^{1}$ Giannina Marcela Chávez, ${ }^{2}$ Heloiza Maria Siqueira Rennó, \\ ${ }^{3}$ Selma Maria Da Fonseca Viegas I
}

Resumo: Compreender a inter-relação da demanda e acessibilidade em saúde, sob a ótica de profissionais e usuários da Estratégia Saúde da Família, foi o objetivo deste estudo. Trata-se de estudo qualitativo, sob o método da Teoria Fundamentada nos Dados e o referencial teórico do Interacionismo Simbólico, com 34 participantes. Da análise originaram 32 códigos in vivo, três códigos teóricos e a categoria central. A vivência do usuário em suas demandas em saúde é interdependente da oferta das açóes, do acesso à saúde, do acolhimento e do cuidado. A alta demanda espontânea impacta na programaçáo das açóes de saúde. O cuidado com a saúde, em sua maior procura, é decorrente do adoecimento. A assistência à saúde foi descrita como humanizada e os problemas vivenciados foram atribuídos ao sistema. As experiências vividas por usuários e profissionais da ESF permitiram explicitar que a inter-relação da demanda e acessibilidade na Estratégia Saúde da Família é correlacionada à alta demanda espontânea, decorrente de uma Atenção Primária fragilizada; à demanda programada restrita a alguns grupos da populaçáo, e à demanda reprimida cada vez mais frequente por restriçóes do acesso e de recursos disponíveis.

> Palavras-chave: necessidades e demandas de serviços de saúde; acesso aos serviços de saúde; Estratégia Saúde da Família; Atenção Primária à Saúde.

\author{
1 Universidade Federal de São \\ João del-Rei, Campus Centro- \\ Oeste. Divinópolis-MG, Brasil \\ (gianninamarcelans@gmail.com). \\ ORCID: 0000-0001-8753-6892 \\ ${ }^{2}$ Enfermagem, Universidade \\ Federal de São João del- \\ Rei, Campus Centro-Oeste. \\ Divinópolis-MG, Brasil \\ (heloizarenno@gmail.com) \\ ORCID: 0000-0002-8142-9313 \\ ${ }^{3}$ Saúde Coletiva, Universidade \\ Federal de São João del- \\ Rei, Campus Centro-Oeste. \\ Divinópolis-MG, Brasil \\ (selmaviegas@ufsj.edu.br). \\ ORCID: 0000-0002-0287-4997
}

Recebido em: 09/01/2020 Aprovado em: 14/06/2020 Revisado em: 30/08/2020 


\section{Introdução}

A Atenção Primária à Saúde (APS) deve ser o contato preferencial dos usuários, a principal porta de entrada e centro de comunicação da Rede de Atenção à Saúde no Sistema Único de Saúde (SUS). Orienta-se pelos princípios da universalidade, acessibilidade, vínculo, continuidade do cuidado, integralidade da atenção, responsabilização, humanização, equidade e participação social (BRASIL, 2017).

A busca por atendimento nos serviços de saúde, em especial na APS, é determinada pelas necessidades de saúde dos usuários, sejam elas individuais ou coletivas. Essas se apresentam como demandas em saúde no cotidiano dos serviços do SUS. A demanda em saúde é caracterizada pela atitude do indivíduo em procurar serviços de saúde, objetivando o acesso e a resolução do que procura. Contudo, existem exceçóes em que a demanda náo se constituirá de necessidades, seja por desconhecimento da população do que realmente precisam, seja pela falta de informação acerca dos problemas vivenciados, impossibilidade de pagar pelos serviços, assim como oferta indisponível de serviços desejados (SOUZA; BOTAZZO, 2013).

A acessibilidade relaciona-se à capacidade de produzir serviços em tempo oportuno, com continuidade do cuidado para responder às necessidades de saúde de usuários. Relaciona-se, também, às características da oferta que podem facilitar ou dificultar a capacidade de acesso das pessoas aos serviços de saúde, e à adequação dos profissionais de saúde e dos recursos tecnológicos utilizados frente às necessidades de saúde dos usuários (DONABEDIAN, 2003).

A abordagem sobre as necessidades de saúde da população pode-se tornar restritiva, uma vez que se trata da premissa de que é possível determinar as verdadeiras necessidades de saúde do indivíduo e da comunidade, quando, de fato, essas são construídas em um contexto social (SOUZA; BOTAZZO, 2013; BRASIL, 2013). Esse processo de construção deve ser constituído por trabalhadores e usuários, de modo que seja possível produzir saúde nas instituiçôes e comunidades (SOUZA; BOTAZZO, 2013).

As demandas de serviços de saúde podem ser caracterizadas como: demanda espontânea, programada e reprimida. É denominada demanda espontânea (DE) aquela em que o indivíduo que comparece à unidade de saúde de forma inesperada, podendo ser por problemas agudos ou por motivo considerado como necessidade de saúde pelo usuário (BRASIL, 2013). A demanda programada (DP), por sua vez, é 
definida como aquela em qual são realizados agendamentos prévios de serviços de saúde. Foi implantada com o intuito de reorganizar o acesso ao SUS e direcionar as demandas da população adstrita, tendo como eixo a promoção à saúde e prevenção de agravos por meio da longitudinalidade (ALMEIDA; FAUSTO; GIOVANELLA, 2011; BRASIL, 2013). Já a demanda reprimida é constituída por usuários que foram desassistidos em determinada situaçáo, e pela desassistência pode levar ao aumento da judicialização da saúde (DANTAS et al., 2015). Essas modalidades de demanda podem, em grande parte, ser acolhidas e resolvidas na APS (BRASIL, 2013).

No Brasil, a Estratégia Saúde da Família (ESF), criada em 1994, tem como objetivo fortalecer a APS no Brasil. A ESF deve

[...] utilizar de tecnologias de cuidado complexas e variadas que devem auxiliar no manejo das demandas e necessidades de saúde de maior frequência e relevância em seu território, observando critérios de risco, vulnerabilidade, resiliência e o imperativo ético de que toda demanda, necessidade de saúde ou sofrimento devem ser acolhidos (BRASIL, 2017, p. 3).

Contudo, estudo evidencia "tensionamento entre as práticas centradas na ampliação da clínica e nas tecnologias leves, e as práticas reducionistas, centradas no modelo biomédico e nas tecnologias duras" (REIS; VIEIRA, 2013).

A China possui um sistema de atendimento de cuidados de saúde em três camadas: atenção primária, hospitais secundários e hospitais terciários. Apesar dessa classificação, as pessoas podem acessar os cuidados primários em todas as instalaçôes nos três níveis, tendo a liberdade de escolher um médico ou centro de cuidados de saúde sem as restriçôes da apólice de seguro de saúde. A China está passando por uma reforma dos cuidados de saúde e os centros de saúde da comunidade (CSC) estão sendo estabelecidos como os provedores de cuidados primários preferidos. Os CSC facilitam o acesso a um profissional de saúde que pode se tornar uma fonte de cuidados habituais básicos (DU et al., 2015). Na província de Guangdong, uma nova política de médico de família foi implantada. Trata-se de um projeto piloto em que os pacientes são encorajados a se inscrever com um médico de família que presta cuidados habituais básicos. $\mathrm{O}$ estudo acrescentou evidências de que, na China, uma fonte de cuidados habituais básicos pode fornecer uma maior qualidade de cuidados primários às pessoas, o que fornece base para o fortalecimento da política de saúde de cuidados básicos (DU et al., 2015).

Na Espanha, a grande maioria da população utiliza o médico de família e ou o pediatra do centro de saúde na busca por atendimento. O usuário é vinculado a um 
médico de família, podendo solicitar atendimento por outro profissional, mediante justificativa. A funçáo de porta de entrada pela APS já era realizada antes das reformas do Sistema Nacional de Salud na década de 80, do século XX. Além disso, em alguns casos, os enfermeiros das equipes de APS realizam o atendimento de primeiro contato ao usuário, embora a função de filtro para a atenção especializada seja exercida por médicos de família (ALMEIDA et al., 2013).

$\mathrm{O}$ atendimento na ESF brasileira, na maioria das vezes, decorre da DE, a partir de necessidades individuais dos usuários, uma vez que os interesses são geralmente por consultas médicas, encaminhamentos às especialidades e distribuição de medicamentos. Além disso, o atendimento desejado pelos usuários é encontrar respostas ao adoecimento, manifestando, espontaneamente, sua demanda no cotidiano dos serviços (SANTOS; PENNA, 2013). Um estudo realizado em quatro capitais brasileiras evidencia que ainda prevalece uma relativa desorganização no atendimento imediato, e as unidades da ESF utilizam mecanismos tradicionais, como, por exemplo, a definição de horários específicos para responder à $\mathrm{DE}$ (ALMEIDA; FAUSTO; GIOVANELLA, 2011). Diante disso, questiona-se: como profissionais e usuários da ESF compreendem demanda espontânea, demanda programada e acessibilidade frente às necessidades de cada um?

Este estudo teve por objetivo compreender a inter-relação da demanda e a acessibilidade em saúde sob a ótica de profissionais e usuários da Estratégia Saúde da Família. ${ }^{1}$

\section{Metodologia}

Trata-se de estudo qualitativo, utilizou-se como método a Teoria Fundamentada nos Dados (TFD) (STRAUSS; CORBIN, 2008) e como referencial teórico, o Interacionismo Simbólico (IS) (BLUMER, 1969). A proposta de se trabalhar a abordagem qualitativa considera que os processos de subjetivaçôes deverão ser analisados, a partir da percepção dos participantes da pesquisa (MINAYO, 2012) que, neste estudo, serão em relação às experiências vividas por profissionais de saúde e usuários na ESF frente às demandas espontânea, programada, reprimida e à acessibilidade.

A TFD é usada quando os pesquisadores estão interessados em fenômenos que envolvem processos sociais, sublinhando experiências e comportamento humano. O objetivo da abordagem da TFD é a geração de teoria que se origina nos dados, 
ou é "fundamentada" nos dados. As principais características dos desenhos da TFD são amostragem teórica e a comparaçáo constante dos dados com as categorias que emergem. A coleta e análise de dados ocorrem simultaneamente e a cada nova coleta, os dados são constantemente comparados e contrastados com conceitos previamente identificados (STRAUSS; CORBIN, 2008).

O IS traduz o significado como um dos mais importantes elementos na compreensão do comportamento humano, das interaçóes e dos processos para alcançar uma compreensão plena do processo social. Possibilita compreender a conduta humana, fundamentada em seus aspectos internos, assim como cada pessoa lida com os acontecimentos ou a realidade em torno de si, e como isso influenciará sua vivência (BLUMER, 1969; MINAYO; 2012).

A coleta de dados foi realizada no período de outubro de 2016 a maio de 2017, em um município de grande porte de Minas Gerais, com população estimada de 234.937 habitantes. Utilizou-se como fontes de evidências a entrevista aberta, intensiva e individual, com roteiro semiestruturado e registros em memorandos: operacionais, direcionados para os procedimentos funcionais da pesquisa; e os memorandos iniciais realizados após cada coleta de dados. O município possui 32 equipes da ESF e estas foram selecionadas por sorteio aleatório, considerando como critério de inclusão "equipes mínimas completas" (BRASIL, 2017, p. 13), e como critério de exclusão, as unidades tradicionais de APS em transição para ESF. Das 32 equipes, 12 (37,5\%) atenderam aos critérios adotados. Este estudo contemplou, como cenário do estudo, cinco equipes de ESF locadas em cinco unidades específicas para cada equipe, com população adscrita entre 2.646 a 7.000 pessoas (Memorando).

$\mathrm{O}$ estudo teve 34 participantes, sendo 16 profissionais de saúde que possuíam vínculo na ESF, no tempo mínimo de seis meses, e 18 usuários, maiores de 18 anos de idade, aptos a responder por si, cadastrados e acompanhados pela ESF e que compareceram à unidade para atendimento na $\mathrm{DE}$ ou na $\mathrm{DP}$ no dia da entrevista. No processo de coleta de dados, foi necessário o acréscimo de quatro perguntas no roteiro de entrevista dos profissionais e três no roteiro dos usuários (Memorando) para aprofundamento de códigos segundo os conceitos que emergiram dos resultados, além de contemplar o processo de análise, conforme o método da TFD, de modo a atingir a saturação teórica dos dados. As entrevistas tiveram duração média de sete a oito minutos, foram gravadas e transcritas na íntegra para posterior análise. Não houve recusa ou desistência de nenhum convidado-participante do 
estudo. A identificação das entrevistas deu-se mediante a letra "E" para representar todos os entrevistados, a letra "P" para identificar profissionais de saúde e letra "U" representando os usuários. A numeração foi descrita segundo a ordem cronológica da coleta $\left(E_{P Y} ; E_{U P} ; E_{P 2} ; E_{U 2} \ldots\right)$.

A análise dos dados deu-se, inicialmente, com a codificação aberta, que é uma fase para a categorizaçáo e a nomeação dos fenômenos. Foi acompanhada de uma investigação dos dados para, comparativamente, descobrir as semelhanças e as diferenças entre eles. Após essa fase, realizou-se o levantamento de questóes sobre os fenômenos aos quais os dados fazem referência (STRAUSS; CORBIN, 2008). Em seguida, procedeu-se à codificação focal, que utilizou os códigos mais significativos e/ou frequentes para analisar minuciosamente os dados. Essa codificação exige a tomada de decisão sobre quais códigos iniciais permitem melhor compreensão analítica para categorizar os dados de forma incisiva e completa. Posteriormente, realizou-se a codificação axial, na qual as categorias foram relacionadas às subcategorias e especificadas as propriedades e as dimensôes de uma categoria, reagrupando os dados fragmentados durante a codificação aberta para dar coerência à análise, e para determinar as condiçôes determinantes, o contexto, as estratégias e as consequências para o fenômeno estudado (STRAUSS; CORBIN, 2008).

Por fim, a codificação teórica especificou as relaçôes possíveis entre as categorias desenvolvidas na codificação focal. Os códigos teóricos levaram à formulação da categoria central: "A teoria da demanda na Estratégia Saúde da Família: espontânea, programada ou reprimida?". Esta categoria conduziu todos os componentes da teoria, ou seja, a categoria central tornou explícita a experiência vivenciada e a compreensão dos participantes da pesquisa sobre o objeto do estudo (STRAUSS; CORBIN, 2008). Este artigo discutirá o código teórico “a inter-relação da demanda" e acessibilidade na ESF.

A pesquisafoi aprovadasobo Parecern $n^{\circ}$ 1.686.000, CAAE: 58465316.1.0000.5545, e todos os participantes voluntários assinaram o Termo de Consentimento Livre e Esclarecido.

\section{Resultados}

O presente estudo contou com 34 participantes, sendo 16 profissionais de saúde e 18 usuários. Em relação à caracterização dos profissionais, 13 (81,3\%) foram mulheres; a média de idade foi de 48 anos; e a média de tempo de trabalho na ESF foi de 9,8 
anos. Participaram cinco enfermeiras, quatro médicos, três técnicas de enfermagem, três agentes comunitários de saúde (ACS) e uma auxiliar de saúde bucal (ASB). Dos nove profissionais de nível superior, sete possuíam especialização em Saúde da Família. Em relação aos usuários, participaram 13 (72,2\%) mulheres, cinco homens e a média de idade foi de 42 anos. Quanto ao nível de escolaridade, nove possuíam nível fundamental incompleto, três com nível fundamental completo, três de nível médio completo, dois possuíam nível superior, e um declarou-se analfabeto. Desses, apenas cinco eram provenientes da DP e oito possuíam algum tipo de plano de saúde.

Da análise do estudo originaram três códigos teóricos: Noçôes de demandas por profissionais e usuários da Estratégia Saúde da Família: espontânea, programada e reprimida; Inter-relação da demanda na Estratégia Saúde da Família; Acesso, acessibilidade e demanda na Estratégia Saúde da Família. Os resultados indicaram 32 códigos in vivo que marcam a alocução e os significados dos participantes da pesquisa frente à demanda na ESF.

Os códigos focais surgiram da comparação dos dados, identificando o contexto, as condiçôes determinantes, as estratégias, as consequências, os comportamentos de profissionais e usuários frente à demanda no cotidiano dos serviços, cenários do estudo, conferindo aos dados analisados a formulação das categorias e da integração teórica. O Interacionismo Simbólico subsidia, sob a ótica dos participantes da pesquisa, a vivência da demanda na ESF. Essa vivência alude a oferta das açóes de saúde, o cuidado com a saúde e o acolhimento. Os profissionais de saúde declaram que a alta DE interfere na programação das ações de saúde. O cuidado com a saúde em grande parte é decorrente do adoecimento. A assistência foi descrita como humanizada pelos usuários, de modo que os problemas vivenciados pelos profissionais e usuários foram atribuídos, em sua maioria, ao sistema.

O paradigma da análise se constituiu das condiçôes determinantes, do contexto, das estratégias e das consequências inerentes à demanda espontânea, programada e reprimida no contexto da ESF e formam as relaçôes teóricas pelas quais as categorias/ códigos teóricos estão relacionadas uma a outra e à categoria central: A teoria da demanda na Estratégia Saúde da Família: espontânea, programada ou reprimida? As três categorias/códigos teóricos trazem a representatividade e a ocorrência dos dados na amostragem teórica. Este manuscrito discute o código teórico "Inter-relação da demanda na Estratégia Saúde da Família", com os respectivos códigos focais "O descuido e/ou cuidado com a saúde" e "O contexto da demanda”, que identificam o 
contexto, as condiçóes determinantes, as estratégias, as consequências da demanda no cotidiano dos serviços, representados em seus códigos in vivo.

Figura 1. Diagrama da representação do fenômeno central da teoria da demanda na ESF

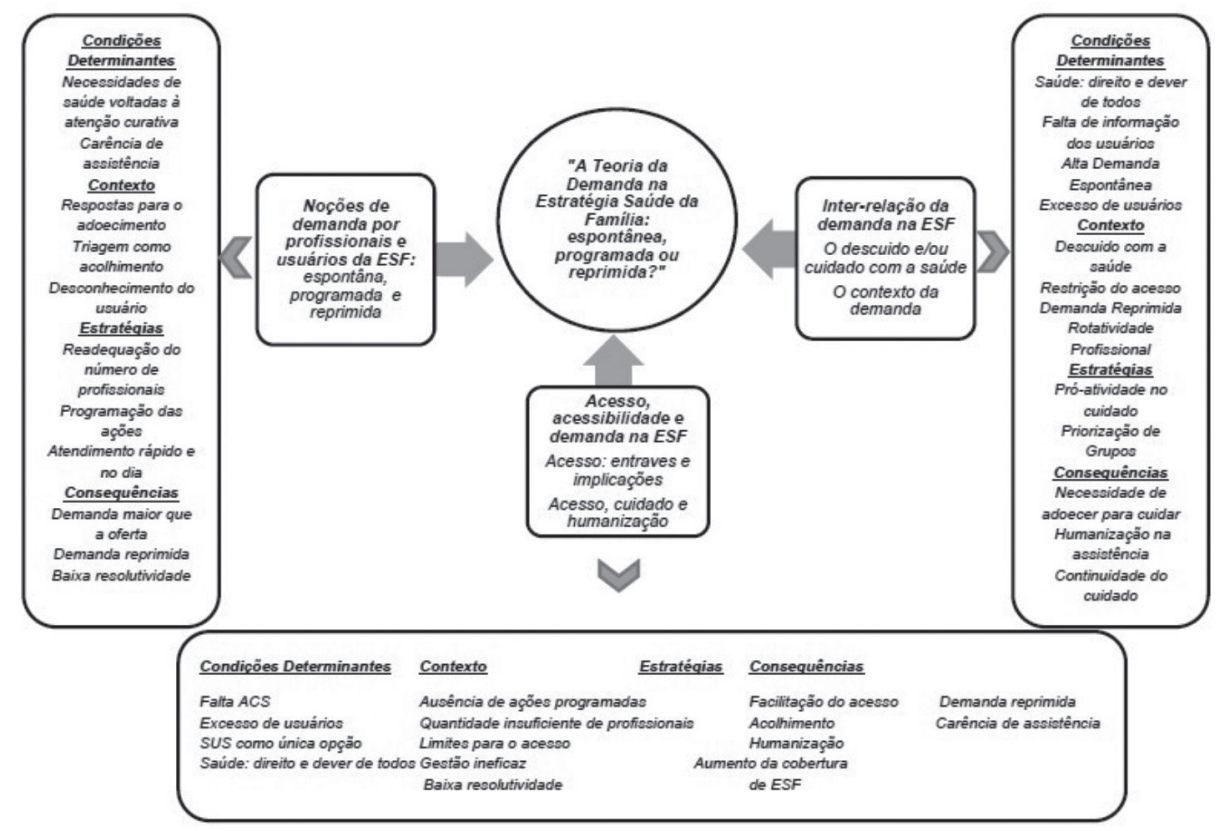

Fonte: os autores

O descuido e/ou cuidado com a saúde foram expressos remetendo ao conceito ampliado de saúde, enfatizando alguns dos seus determinantes e condicionantes.

\section{Condiçóes determinantes}

Saúde é um direito de todos. O principal na vida de uma pessoa eu acho que é a saúde, sabe? O que vem em primeiro lugar, depois de Deus, é a saúde, porque se você tem saúde você tem a coragem, a vontade, a esperança, a vontade de viver bem, não é? Ter uma qualidade de vida $\left(\mathrm{E}_{\mathrm{U} 18}\right)$.

Uai, cuido como o SUS pode oferecer para nós. Se o SUS consegue oferecer condições e estiver cuidando direitinho da saúde, nós estamos em cima $\left(\mathrm{E}_{\mathrm{U} 14}\right)$.

Eu cuido da minha saúde tendo em mim uma visão, até acabei de falar isso com o Doutor na consulta, que quem cuida da saúde da gente é a gente $\left(\mathrm{E}_{\mathrm{U} 2}\right)$. 


\section{Contexto}

Cuido mal. Bem mal [...] Ah... não alimento na hora certa, não faço o exercício que o médico me pede [...] Náo tenho vontade $\left(\mathrm{E}_{\mathrm{U1}}\right)$.

Está faltando ainda muito entendimento sobre a saúde, tem muita gente que, às vezes, deixa para lá, não quer se cuidar, não quer perder tempo. Outros não querem, tem uma doença, um problema, está com vergonha, não quer assumir $\left(\mathrm{E}_{\mathrm{US}}\right)$.

Ah, eu sou muito relapso com a minha saúde. Porque eu não tenho tempo, trabalho muito, as empresas hoje não liberam a gente para cuidar da saúde, então eu sou muito relapso mesmo $\left(\mathrm{E}_{\mathrm{U} 13}\right)$.

\section{Estratégias}

Eu gosto, principalmente de massas, doces, chocolate. Eu não posso comer, mas de vez em quando eu como. Diminuí, mas não deixei de comer. Aí, bastante verdura, salada [...] fiz um cirurgia em 2014 [...] daí para cá eu comecei a fazer caminhada, eu até inclusive estava fazendo hidroginástica e pilates, aí dei uma parada porque é só pagando, nenhum plano cobre [...] eu estou encostada, não tenho ganho, então é mais complicado, o custo de vida está muito alto $\left(\mathrm{E}_{\mathrm{US}}\right)$.

Eu procuro me alimentar bem. O meu marido estava muito gordinho, aí a gente cortou algumas coisas que não são tão benéficas, o refrigerante e o doce. Então, praticamente a gente quase não consome açúcar, é... óleo e fritura zerado, e a gente usa mais é azeite. Comer bastante fruta, tomar suco natural. Eu não pratico exercício físico, sou preguiçosa, estou necessitando disso $\left(\mathrm{E}_{\mathrm{U} 6}\right)$.

\section{Consequências}

Uai, agora que eu estou cuidando, porque eu náo ligava. Foi até eu descobrir que eu tinha pressão alta, porque eu nunca fiz acompanhamento de pressão. Depois que eu engravidei que eu descobri que, na minha família, todo mundo tem pressão alta. Então agora eu estou começando a cuidar da saúde por causa da bebê. Eu não ligava náo para minha saúde não. Porque eu bebia demais, fumava demais, agora eu maneirei $\left(\mathrm{E}_{\mathrm{U} 10}\right)$.

Eu acho que eu num cuido muito bem, eu como muita coisa que faz mal, sabe, muito doce. Até eu vim fazer o exame e a glicose estava alta, 140 da última vez, mas agora eu estou até conseguindo, vamos ver se eu consigo $\left(\mathrm{E}_{\mathrm{U} 17}\right)$.

\section{O contexto da demanda vivenciado pelos profissionais de saúde e usuários:}

\section{Condiçốes determinantes}

Sempre tem demanda espontânea. Tem também o pessoal que vem agendado, a maioria, em minha opiniâo, é por falta de conhecimento mesmo de como funciona o SUS, como que ele vai procurar o atendimento, sabe? $\left(\mathrm{E}_{\mathrm{P} 1}\right)$ 
Muito grande a demanda! A gente está com um número muito elevado de usuários, porque na verdade, essa ESF já tinha que ser dividida, não foi até agora! A gente está com quase 7.000 usuários $\left(\mathrm{E}_{\mathrm{P} 7}\right)$.

Eu acho que a procura do paciente é por ele não ter tanta tolerância para aguardar consulta, por considerar que o problema dele é mais urgente [...] Eu acho tão difícil essa parte da demanda espontânea, sabe? Eu acho que é uma questão cultural, uma questáo social, de organização da equipe. Eu, sinceramente, não tenho uma proposta de como organizar isso, de como acolher mais. O que eu percebo em todos esses anos que eu estou aqui, muitas vezes, que é do próprio paciente e, às vezes, por falta de acolhimento, porque esse paciente veio, ele foi mal recebido, e ou ele veio e a consulta demorou demais, e ele conseguiu acesso de outra forma mais fácil. Então, ele tenta de novo pela forma mais fácil $\left(\mathrm{E}_{\mathrm{P} 11}\right)$.

Quando é um caso mais sério, rápido, eu vou para UPA [...] Ah... hoje em dia está grande a demanda porque ninguém está tendo condições de pagar um plano de saúde, não é? Então, tem que ir para UPA ou para os atendimentos no posto $\left(\mathrm{E}_{\mathrm{U} 1}\right)$.

\section{Contexto}

A gente deixa fixo um horário, até oito e meia a triagem, para estar restringindo e dificultando um pouquinho, para ver se eles vêm mais agendar consulta do que vir em demanda espontânea. Mas essa demanda continua sendo enorme! [...] Aqui é bem grande o fluxo, acho que pela facilidade mesmo no atendimento. Não acredito que seja culpa também do agendamento, mas é que o pessoal aqui gosta muito do médico, então eu acho que isso faz com que eles venham mais vezes. E como a gente ainda não tem aquele acompanhamento programado, principalmente para hipertenso, diabético que poderia estar programando, a pessoa não sai daqui sabendo quando ela vai voltar, entâo ela acha que ela tem que vir toda semana. Então temos um fluxo bem grande de demanda espontânea $\left(\mathrm{E}_{\mathrm{P} 2}\right)$.

Procurar eles procuram muito. Só que, assim, as pessoas geralmente chegam querendo o atendimento na hora, independente do tipo de problema que tem. Mesmo que é uma rotina, as pessoas sempre chegam querendo ser atendidas na hora. [...] Mas chega caso que, às vezes, era para UPA e vem para cá, aí a gente tem que orientar $\left(\mathrm{E}_{\mathrm{P} 5}\right)$.

Tem os usuários que são assíduos, vem preocupado com a saúde para fazer check-up porque viu em televisão, viu em internet determinadas doenças. E têm aqueles que você dificilmente pega para trazer, e têm os pacientes crônicos que são os hipertensos, os diabéticos, os asmáticos, que vêm por causa da agudização da doença $\left(\mathrm{E}_{\mathrm{P} 15}\right)$.

Todos os dias às sete horas tem esse atendimento de demanda. Eles passam por uma triagem, havendo a necessidade, aí eles são atendidos até no mesmo dia, passa pelo médico, entendeu? A técnica de Enfermagem e enfermeira fazem até umas dez triagens por dia. E há necessidade de estarem passando pelo médico quase todas $\left(\mathrm{E}_{\mathrm{p} 7}\right)$. 


\section{Estratégias}

A demanda programada é por agenda, que é aberta no início do mês e aí marca enquanto tiver vaga. E a espontânea é diariamente, é de manhã até oito e meia $\left(\mathrm{E}_{\mathrm{p} 8}\right)$.

Aqui nós estamos com excesso de famílias, 266 famílias cadastradas e vinculadas. Então a gente dá prioridade para hipertenso, diabético, gestante, recém-nascido, acamado, e depois o tempo que sobra a gente vai às pessoas supostamente sãs $\left(\mathrm{E}_{\mathrm{P} 10}\right)$.

O acompanhamento é feito pelo agente comunitário, o primeiro contato é dele, depois vem o pessoal da recepção que seria o técnico de Enfermagem e a enfermeira, e em terceiro seria o contato com o médico. Agora, devido à longitudinalidade, o tempo de exercício da profissão no local, a gente já conhece cada um dos pacientes, então você já sabe mais ou menos a queixa que aquele paciente tem e o que vai fazer com ele. Então, a importância da longitudinalidade é esse conhecimento da família, então você já conhece as doenças de cada família, você já conhece cada paciente, a cultura deles, você conhece o tipo de vida deles, então isso aí é muito importante no tratamento da saúde deles $\left(\mathrm{E}_{\mathrm{P} 15}\right)$.

Triagem e acolhimento. Eu não gosto desse termo triagem, sabe [...] a gente chama de urgência para ver se também o paciente consegue introjetar: "não, isso não é tão urgente, eu posso aguardar". Porque uma triagem é uma coisa mais superficial, eu acho, e triagem para mim se fosse pensar é... medir, pesar esse paciente, que é muito diferente do acolhimento, o acolhimento é escuta, não é? É você direcionar o paciente para o que ele veio, às vezes não é para mim, não é para o médico, não é para o enfermeiro, é para o dentista, ou ele veio só para buscar uma receita, então eu acho que é bem diferente o acolhimento da triagem. É esse paciente sentir que ele foi valorizado, que a queixa foi valorizada, e vai ser até mais fácil dele receber um não se ele não for um caso de urgência $\left(\mathrm{E}_{\mathrm{P} 11}\right)$.

\section{Consequências}

Eu acho que essa demanda que não é programada, ela tira bastante tempo da gente. E eu me sinto super sobrecarregada com essa demanda, com esse fluxo enorme, que a gente não consegue estabelecer um foco para poder melhorar. Sabemos que têm que melhorar, mas têm coisas que não dependem da gente, está fora do nosso alcance $\left(\mathrm{E}_{\mathrm{p} 2}\right)$.

$\mathrm{Na}$ consulta médica, essa demanda espontânea interfere na nossa rotina sim, suga muito a gente $\left(\mathrm{E}_{\mathrm{P} 11}\right)$.

Aqui eu só tenho a elogiar! Nunca fui mal atendido, o pessoal atende com atenção, com respeito. Para dizer a verdade, eu até acabei de fazer elogios ali para o Doutor. O jeito humanizado que ele atende, e já vi outras pessoas do bairro aqui elogiá-lo, entendeu? Eu fiz questão de falar isso com ele, porque eu fico satisfeito de ser respeitado e demonstrar também respeito e reconhecimento $\left(\mathrm{E}_{\mathrm{U} 2}\right)$.

O problema não é deles (profissionais), é do Sistema que não ajuda, o Sistema Único. Então, eles são excelentes pessoas para mim, sempre me tratam bem aqui, todos os profissionais [...] É muito humanizado $\left(\mathrm{E}_{\mathrm{U} 14}\right)$. 


\section{Discussão}

A saúde foi expressa pelos usuários da ESF como direito de todos e dever do Estado, e de ser essencial para garantia do bem-estar e da qualidade de vida. Entretanto, não se pode excluir o indivíduo como o principal responsável por sua saúde, de ser o protagonista e vislumbrar o autocuidado. A percepçáo sobre o cuidado com a saúde, neste estudo, compara-se com o estudo realizado no município do Rio de Janeiro, Brasil, cuja representação de saúde pelo usuário caracteriza o estar saudável como a ausência de doenças, e por ter aptidão para realizar atividades laborais durante a vida (REIGADA; ROMANO, 2015).

O autocuidado muitas vezes não é realizado pelos usuários, pois mesmo reconhecendo a necessidade de cuidar da saúde ou ter controle da doença, esses não conseguem desenvolver um comportamento de proatividade (TESTON; SALES; MARCON, 2017). A descrição do cuidado com a saúde, neste estudo, considera as práticas de alimentação saudável, a atividade física e a cessação de hábitos de vida como o alcoolismo e o tabagismo. O descuido com a saúde foi manifesto na falta de adesão às recomendaçôes dos profissionais de saúde, na falta de vontade para cuidar-se, na falta de tempo do usuário que se dedica ao trabalho, pelas condiçôes socioeconômicas e na dificuldade de aceitação da doença. Evidencia-se a necessidade de adoecer como determinante para a realização do cuidado, de modo que a doença seja o principal motivo pela busca por atendimentos nos serviços de saúde (PENNA; FARIA; REZENDE, 2014).

O ambiente familiar e de trabalho são fatores que influenciam a adoção de medidas de autocuidado pelos usuários. O processo de trabalho dos serviços de saúde e as recomendaçôes dos profissionais muitas vezes não são personalizados e apresentam uma distância da realidade vivenciada (TESTON; SALES; MARCON, 2017).

As condiçôes socioeconômicas, quando associadas às necessidades de saúde podem constituir desigualdades sociais e iniquidades em saúde. "A luta pelo SUS depende da luta contra a desigualdade” (CAMPOS, 2018, p. 1710). Assim, o SUS “é exclusivamente responsável por $75 \%$ da população, além de realizar serviços voltados para toda a sociedade e conta com apenas $46 \%$ dos recursos destinados à saúde. Em um contexto de desiguais, $54 \%$ do gasto em saúde acontecem no setor privado, que atende a apenas $25 \%$ da população" (CAMPOS, 2018, p.1708). 
Estudo conduzido na província canadense de Quebec revelou que condiçôes de vida pouco saudáveis impedem as pessoas que vivem na pobreza de acessar cuidados de saúde de qualidade e manter uma boa saúde. Além disso, a complexidade da organização e do funcionamento do sistema de saúde tem impacto negativo nas interações com os profissionais de saúde. São necessárias mudanças nas políticas e na prática para abordar essas barreiras e alcançar maior equidade, e oferecer cuidados mais receptivos às pessoas que vivem na pobreza. Garantir o acesso aos cuidados de saúde primários, oportunos e adequados para pessoas em desigualdades sociais é um problema para todos os países, mesmo aqueles com sistemas de saúde universais. Há uma escassez de informaçóes sobre como as pessoas que vivem em contexto de privação material e social percebem barreiras no sistema de saúde (LOIGNON et al., 2015).

A demanda, neste estudo, se contextualiza no atendimento à DE que é maior quando comparado à programada. $\mathrm{O}$ incipiente conhecimento do usuário sobre os pressupostos da ESF e das atribuiçôes da equipe, além da população cadastrada acima do recomendado para uma equipe de ESF foram determinantes, segundo os participantes desta pesquisa, para a alta DE. Um estudo (AQUINO et al., 2014) corrobora este achado, ao evidenciar que o usuário, por desconhecer a organização do serviço, irá procurar pelo meio de acesso mais rápido e fácil, de modo a atender sua necessidade de saúde em DE.

O excesso de usuários/famílias cadastradas dificulta a organização e oferta de serviços prestados pela equipe. Conforme recomendado na Portaria n ${ }^{\circ}$ 2436/2017, "cada equipe de saúde da família deve ser responsável por, no máximo, 3.500 pessoas, sendo a média recomendada de 2.000 pessoas, respeitando critérios de equidade para esta definição. Recomenda-se que o número de pessoas por equipe considere o grau de vulnerabilidade das famílias daquele território, sendo que, quanto maior o grau de vulnerabilidade, menor deverá ser a quantidade de pessoas por equipe" (BRASIL, 2017, p. 12). Os resultados deste estudo apresentam a necessidade de reorganização das equipes pela gestáo municipal e, principalmente, a ampliação da cobertura assistencial mediante a implantação de novas equipes.

A atitude de procurar atendimento na Unidade de Pronto Atendimento (UPA), como primeira opção, contribui para o aumento da demanda não específica nessa unidade, visto que deveria realizar, prioritariamente, a assistência voltada às urgências e emergências (CAMPOS et al., 2014). Essa alta demanda nos serviços de emergência 
desencadeia estresse tanto para os usuários, que buscam por atendimento digno e de qualidade, quanto para os profissionais, que têm como dever realizar o atendimento de todos os indivíduos e dar resoluçáo aos problemas encontrados no cotidiano de trabalho em UPA (RONCALI et al., 2017).

A triagem teve grande destaque nos relatos dos profissionais e usuários do estudo. As rotinas de atendimento das unidades são semelhantes, uma vez que todas realizam uma triagem com intuito de resolver a queixa do usuário e encaminhar ao atendimento médico. Isto reflete a falta de acolhimento que não é realizado de maneira qualificada, com vistas à resolutividade da demanda do usuário, decorrente de uma necessidade individual. O acolhimento associado ao fluxo da DE caracterizase como meio de acesso, e não como atendimento integral e equânime (TESTON; SALES; MARCON, 2017; SOUSA et al., 2014). Além disso, o acesso ao cuidado relacionado à $\mathrm{DE}$ é determinado pelo restrito horário de uma hora e meia no período matutino em uma triagem, realizada pelo enfermeiro ou técnico de enfermagem, que avalia a necessidade de atendimento médico no dia.

A discussão do acolhimento na ESF, cujo objetivo é trabalhar a escuta qualificada e o direcionamento das ações de saúde, deve ser considerada como essencial e prioritária para que os profissionais não realizem somente uma triagem ou classificação de risco. A mudança do modelo assistencial vigente, baseado na doença e na queixa, dependerá da reorganização do sistema e dedicação do profissional (REIGADA; ROMANO, 2015). O acolhimento como estratégia e política permite a construção de um relacionamento entre usuário e equipe baseado na confiança e no comprometimento, de modo a contribuir no processo de fortalecimento e legitimação da APS (MARQUES-FERREIRA; BARREIRA-PENQUES; SANCHES-MARIN, 2014).

É “importante ressaltar que a alta prevalência de demandas resolvidas contribui também para a construção da confiança e o aumento do vínculo entre os usuários e os serviços" (PROTASIO et al., 2017, p. 1.838). A priorização de alguns grupos para as açóes programáticas gera uma demanda reprimida no âmbito da ESF. Percebe-se uma restrição ao acesso, de modo que as açôes de saúde estão voltadas, principalmente à saúde materno-infantil e às pessoas com doenças crônicas, como hipertensão arterial sistêmica e diabetes mellitus. A programação de ações associada à priorização de determinados grupos ou faixas etárias dificulta o acesso, a acessibilidade e, consequentemente, induz o usuário a buscar atendimento na DE, o que desvaloriza a ESF quanto aos seus princípios e responsabilização (NORMAN; TESSER, 2015). 
No contexto da resolutividade, percebe-se mais uma barreira de acesso, pois está relacionada, principalmente, aos encaminhamentos para consultas especializadas, cuja oferta é insuficiente, decorrente da ausência de recursos humanos ou de exames especializados e a distribuição desses é realizada mediante cotas mensais para a ESF e triadas por uma central de regulação (SOUSA et al., 2014). Frente a isso, evidenciase uma demanda reprimida, cada vez mais frequente, e que não há estratégias de enfrentamento estabelecidas pelas equipes de ESF e pelos gestores do Sistema.

A longitudinalidade do cuidado à assistência ao usuário e sua família foi evidenciada. Essa é referida como atendimento em saúde, realizado por uma equipe com objetivo de acolher o usuário por meio da continuidade do cuidado ao longo da vida e, consequentemente, promover o fortalecimento da ESF. A rotatividade profissional acarreta maior fragilidade no vínculo entre equipe e comunidade, de modo a comprometer a efetividade do serviço (FRANK et al., 2015). Para alcançar a longitudinalidade, deve-se contemplar açôes que incentivem os profissionais a se manter nas equipes em que estão vinculados. Além disso, é desejável fixar profissionais capacitados para identificar as necessidades da população (PAULA et al., 2016).

A humanização na assistência foi expressa pelos usuários da ESF frente ao atendimento e condutas adotadas pelos profissionais. A relação de reciprocidade entre usuário e profissional nos remete às propostas de acolhimento que promovem a humanização da assistência prevista na Política Nacional de Humanização. Dessa forma, compreende-se a humanização como método de construção de um modelo de atenção à saúde que considere o ser humano em sua dignidade e contexto, que estabeleça o vínculo, e que consolide a integralidade em saúde (OLIVEIRA JUNIOR; SOUZA, 2013). Destarte, a organização e a distribuição das açôes dos serviços de saúde devem responder de modo satisfatório às demandas e necessidades de saúde (VIEGAS; PENNA, 2012).

As experiências vividas por usuários e profissionais da ESF, analisadas sob a Teoria Fundamentada nos Dados e no Interacionismo Simbólico, permitiram explicitar que a inter-relação da demanda e a acessibilidade na ESF é constituída por uma alta DE, decorrente de uma APS fragilizada; uma demanda programada restrita a alguns grupos da população e uma demanda reprimida cada vez mais frequente no cotidiano dos serviços de saúde, o que restringe a acessibilidade à saúde . Dessa forma, os participantes da pesquisa demonstraram suas noçôes sobre demanda em saúde e acessibilidade, como se dá a inter-relação das demandas em busca de acesso 
à saúde, denotando as vivências de usuários e profissionais da ESF, suas percepçóes e expectativas quanto à atenção à saúde e acessibilidade no âmbito do SUS.

Como limitação deste estudo, considera-se a ausência da participação dos gerentes dos setores sanitários do município, devido à rotatividade e por não atenderem ao critério de inclusão.

\section{Considerações finais}

A inter-relação da demanda e a acessibilidade evidencia a dinâmica cotidiana na Estratégia Saúde da Família, que se relaciona intimamente com os meios de acesso, com a humanização na assistência e ressalta a necessidade de acolhimento.

Evidenciou-se o descuido com a saúde pelos usuários, configurando a busca pelos serviços de saúde no momento do adoecimento em DE. Contudo, percebe-se que os usuários buscam alternativas para cuidar da saúde após a experiência com a doença. Além da doença, outros fatores determinam a procura por atendimento: o contexto cultural, as condiçôes socioeconômicas e o desconhecimento do fluxo do sistema. Considerando a procura e a capacidade de oferta de açóes em saúde, estas estão diretamente associadas ao número excessivo de usuários para uma equipe de Saúde da Família e à falta de profissionais de saúde e do ACS. A demanda reprimida foi atribuída à baixa resolutividade e restrições de acesso na ESF.

Como contribuiçôes, este estudo apresenta subsídios para que os profissionais de saúde, usuários e gestores possam traçar estratégias de enfrentamento para as dificuldades de acessibilidade à saúde, tendo a ESF como uma das portas de entrada no sistema, e a indicação de replicação da Teoria da Demanda na Estratégia Saúde da Família em outras realidades. ${ }^{2}$

\section{Referências}

ALMEIDA, P. F.; FAUSTO, M. C. R.; GIOVANELLA, L. Strengthening primary health care: a strategy to maximize coordination of care. Rev Panam Salud Publica, v. 29, n. 2, p. 84-95. 2011. Disponível em: https://www.ncbi.nlm.nih.gov/pubmed/21437365

ALMEIDA, P. F. et al. Estratégias de integração entre atenção primária à saúde e atenção especializada: paralelos entre Brasil e Espanha. Saúde debate, v. 37, n. 98, p. 400-415, 2013. Disponível em: http://www.scielo.br/scielo.php?script=sci_arttext\&pid=S0103$11042013000300004 \& \operatorname{lng}=$ en. 
AQUINO, J. M. et al. Participação comunitária no contexto da atenção básica em saúde na perspectiva de usuários. Rev Pesquisa Cuidado Fundamental, v. 6, n. 1, p. 364-377, jan./mar. 2014. Disponível em: http://www.redalyc.org/html/5057/505750621027/

BLUMER, H. Symbolic Interactionism: perspective and method. Englewood Cliffs: PrenticeHall, 1969.

BRASIL. Ministério da Saúde. Portaria no 2.436, de 21 de setembro de 2017. Aprova a Política Nacional de Atenção Básica, estabelecendo a revisão de diretrizes para a organização da Atenção Básica, no âmbito do Sistema Único de Saúde (SUS). Brasília: 2017. Disponível em: http:// bvsms.saude.gov.br/bvs/saudelegis/gm/2017/prt2436_22_09_2017.html

. Ministério da Saúde. Secretaria de Atenção à Saúde. Departamento de Atenção Básica. Acolhimento à demanda espontânea. 1. ed.; 1. reimpr. Brasília: 2013. Disponível em: http:// bvsms.saude.gov.br/bvs/publicacoes/acolhimento_demanda_espontanea_cab28v1.pdf

CAMPOS, G. W. S. SUS: o que e como fazer? Ciênc. saúde coletiva, v. 23, n.6, p. 1707-1714, jun. 2018. Disponível em: http://www.scielo.br/scielo.php?script=sci_arttext\&pid=S1413$81232018000601707 \& \operatorname{lng}=$ pt\&nrm=iso

CAMPOS, R. T. O. et al. Avaliação da qualidade do acesso na atenção primária de uma grande cidade brasileira na perspectiva dos usuários. Saúde debate, v. 38, n. esp., p. 252-264, 2014. Disponível em: http://www.scielo.br/pdf/sdeb/v38nspe/0103-1104-sdeb-38-spe-0252.pdf

DANTAS, A. et al. O fenômeno da judicialização da saúde como estratégia de acesso aos serviços de saúde. In: CONASS. Direito à Saúde. Para entender a gestão do SUS. Brasília: CONASS. $1^{a}$ ed. 2015. Disponível em: http://www.conass.org.br/biblioteca/pdf/colecao2015/ CONASS-DIREITO_A_SAUDE-ART_19.pdf

DONABEDIAN, A. An introduction to quality assurance in health care. New York: Oxford University, 2003.

DU, Z. et al. Usual source of care and the quality of primary care: a survey of patients in Guangdong province, China. Int J Equity Health, v. 14, p. 60, Jul 2015. Disponível em: https:// www.ncbi.nlm.nih.gov/pubmed/26227113

FRANK, B. R. B. et al. Avaliação da longitudinalidade em unidades de Atenção Primária à Saúde. Saúde debate, v. 39, n. 105, p. 400-410, June 2015. Disponível em: http://www.scielo.br/ scielo.php?script=sci_arttext\&pid=S0103-11042015000200400\&lng=en\&nrm=iso

LOIGNON, C. et al. Perceived barriers to healthcare for persons living in poverty in Quebec, Canada: the EQUIhealThY project. Int J Equity Health, v. 14, p. 4, 2015. Disponível em: https:// equityhealthj.biomedcentral.com/articles/10.1186/s12939-015-0135-5

MARQUES-FERREIRA, M. L. S.; BARREIRA-PENQUES, R. M. V.; SANCHES-MARIN, M. J. Acogida en la percepción de los enfermeros de la atención primaria a la salud. Aquichán, 
v. 14, n. 2, p. 216-225, May 2014. Disponível em: http://aquichan.unisabana.edu.co/index.php/ aquichan/article/view/3197

MINAYO, M. C. S. Análise qualitativa: teoria, passos e fidedignidade. Ciênc. saúde coletiva, v. 17, n. 3, p. 621-626, mar. 2012. Disponível em: http://www.scielo.br/scielo.php?script=sci_ arttext\&pid=S1413-81232012000300007\&lng=en\&nrm=iso

NORMAN, A. H.; TESSER, C. D. Acesso ao cuidado na Estratégia Saúde da Família: equilíbrio entre demanda espontânea e prevenção/promoção da saúde. Saude soc, v. 24, n. 1, p. 165-179, mar. 2015. Disponível em: http://www.scielo.br/scielo.php?script=sci_arttext\&pid=S0104$12902015000100165 \& \operatorname{lng}=$ en $\&$ nrm $=$ iso

OLIVEIRA JUNIOR, J. C.; SOUZA, M. K. B. The humanization in the basic health care services: conceptions of health professionals. Rev enferm UFPE on line, v. 7, n. 5, p. 43707, 2013 Disponível em: https://periodicos.ufpe.br/revistas/revistaenfermagem/article/ viewFile/11676/13855

PAULA, W. K. A. S. et al. Avaliação da atenção básica à saúde sob a ótica dos usuários: uma revisão sistemática. Rev. esc. enferm. USP, v. 50, n. 2, p. 335-345, abr. 2016. Disponível em: http://www.scielo.br/scielo.php?script=sci_arttext\&pid=S0080-62342016000200335\&lng= en\&nrm=iso

PENNA, C. M. M.; FARIA, R. S. R.; REZENDE, G. P. Acolhimento: triagem ou estratégia para universalidade do acesso na atenção à saúde? Rev Min Enferm, v. 18, n. 4, p. 815-822, outdez 2014. Disponível em: http://www.reme.org.br/artigo/detalhes/965

PROTASIO, A. P. L. et al. User satisfaction with primary health care by region in Brazil: 1st cycle of external evaluation from PMAQ-AB. Ciênc saúde coletiva, v. 22, n. 6, p. 18291844, 2017. Disponível em: <http://www.scielo.br/scielo.php?script=sci_arttext\&pid=S141381232017002601829\&lng=en\&nrm=iso>.

REIGADA, C. L. L.; ROMANO, V. F. Comunicação e percepçóes sobre saúde: o olhar dos usuários na Estratégia Saúde da Família. Saúde em Redes, v. 1, n. 2, p. 13-19, 2015. Disponível em: http://revista.redeunida.org.br/ojs/index.php/rede-unida/article/view/588

REIS, F.; VIEIRA, A. C. Demandas, construçôes e desafios vivenciados por terapeutas ocupacionais na atenção primária à saúde. Rev Bras Promoção da Saúde, v. 26, v. 3, p. 356-364. 2013. Disponível em: http://periodicos.unifor.br/RBPS/article/view/2938

RONCALLI, A. A. et al. Protocolo de Manchester e população usuária na classificação de risco: visão do Enfermeiro. Rev Baiana Enferm., v. 31, n. 2, p. e16949. 2017. Disponível em: https:// portalseer.ufba.br/index.php/enfermagem/article/view/16949

SANTOS, T. V.; PENNA, C.M.M. Demandas cotidianas na atenção primária: o olhar de profissionais da saúde e usuários. Tex Contexto Enferm, v. 22, n. 1, p. 149-156, mar 2013. Disponível em: http://www.scielo.br/pdf/tce/v22n1/pt_18.pdf 
SOUSA, F. O. S. et al. Do normativo à realidade do Sistema Único de Saúde: revelando barreiras de acesso na rede de cuidados assistenciais. Ciênc. saúde coletiva, v. 19, n. 4, p. 1283-1293, abr. 2014. Disponível em: http://www.scielo.br/scielo.php?script=sci_arttext\&pid=S141381232014000401283\&lng=en\&nrm=iso

SOUZA, C. R.; BOTAZZO, C. Construção social da demanda em saúde. Physis, v. 23, n. 2, p. 393-413, jun. 2013. Disponível em: http://www.scielo.br/scielo.php?script=sci_ arttext\&pid=S0103-73312013000200005\&lng=en\&nrm=iso

STRAUSS, L. A.; CORBIN, J. Pesquisa qualitativa: técnicas e procedimentos para o desenvolvimento de teoria fundamentada. 2. ed. Porto Alegre: Artmed, Bockman, 2008.

TESTON, E. F.; SALES, C. A.; MARCON, S. S. Perspectivas de indivíduos com diabetes sobre autocuidado: contribuiçóes para assistência. Esc. Anna Nery, v. 21, n. 2, e20170043, 2017. Disponível em: http://www.scielo.br/scielo.php?script=sci_arttext\&pid=S1414$81452017000200214 \& \operatorname{lng}=$ en $\&$ nrm $=$ iso

VIEGAS, S. M. F.; PENNA, C. M. M. O vínculo como diretriz para a construção da integralidade na estratégia saúde da família. Rev Rene, v. 13, n. 2, p. 375-85, 2012. Disponível em: http://periodicos.ufc.br/rene/article/view/3930

\section{Notas}

${ }^{1}$ Pesquisa: "Demanda espontânea e programática na Estratégia Saúde da Família: a teoria fundamentada em dados”, CAAE: 58465316.1.0000.5545.

${ }^{2}$ G. M. Chávez participou da elaboração do projeto, coleta e análise de dados e da redação do artigo. H. M. S. Rennó contribuiu com a revisão crítica e aprovaçáo da versão final do artigo. S. M. da F. Viegas responsabilizou-se pela elaboração do projeto, coleta e análise de dados, redação e aprovação da versão final do artigo. 


\section{Abstract}

\section{The inter-relation of demand and accessibility in the Family Health Strategy}

This study aimed to assess the interrelationship of health demand and accessibility, from the point of view of professionals and users of the Family Health Strategy. It is a qualitative study, using the method based on Data Based Theory and the theoretical reference of Symbolic Interactionism, with 34 participants. From the analysis originated 32 codes in vivo, three theoretical codes and the central category. The user's experience in their health demands is interdependent in the offer of actions, access to health, care and welcoming. The high spontaneous demand impacts on the programming of health actions. Health care, in its greatest demand, is due to illness. Health care was described as humanized and the problems experienced were attributed to the system. The experiences of ESF users and professionals made it possible to make explicit that the interrelationship of demand and accessibility in the Family Health Strategy correlates with the high spontaneous demand resulting from fragile Primary Care; to the programmed demand restricted to some groups of the population, and to the repressed demand increasingly frequent by restrictions of access and available resources.

Keywords: health services needs and demand; health services accessibility; Family Health Strategy; Primary Health Care. 